\title{
Anti-interleukin-2 receptor antibodies-basiliximab and daclizumab-for the prevention of acute rejection in renal transplantation
}

This article was published in the following Dove Press journal:

Biologics: Targets \& Therapy

17 June 2009

Number of times this article has been viewed

\section{Junichiro Sageshima \\ Gaetano Ciancio \\ Linda Chen \\ George W Burke III}

DeWitt Daughtry Family Department of Surgery, Division of Kidney and Pancreas Transplantation,

The Lillian Jean Kaplan Renal

Transplant Center, University

of Miami Leonard M. Miller School

of Medicine, Miami, FL, USA
Correspondence: Gaetano Ciancio Department of Surgery, Division of Transplantation, University of Miami Miller School of Medicine,

Post Office Box 012440 (R-440),

Miami, FL 33I0I, USA

Tel +l 3053555111

Email gciancio@med.miami.edu
Abstract: The use of antibody induction after kidney transplantation has increased from $25 \%$ to $63 \%$ in the past decade and roughly one half of the induction agent used is antiinterleukin-2 receptor antibody (IL-2RA, ie, basiliximab or daclizumab). When combined with calcineurin inhibitor (CNI)-based immunosuppression, IL-2RAs have been shown to reduce the incidence of acute rejection, one of the predictors of poor graft survival, without increasing risks of infections and malignancies in kidney transplantation. For low-immunological-risk patients, IL-2RAs, as compared with lymphocyte-depleting antibodies, are equally efficacious and have better safety profiles. For high-risk patients, however, IL-2RAs may be inferior to lymphocyte-depleting antibodies for the prophylaxis of acute rejection. In an effort to reduce toxicities of other immunosuppressive medications without increasing the risk of acute rejection and chronic graft loss, IL-2RAs have often been combined with steroid- and CNI-sparing immunosuppression protocols. More data support the benefits of early steroid withdrawal with IL-2RA in low-risk patients, but preferred induction therapy for high-risk patients has yet to be determined. Although CNI-sparing protocols with IL-2RA may preserve renal function and improve long-term survival in selected patients, further studies are needed to identify those who benefit most from this strategy.

Keywords: basiliximab, daclizumab, interleukin-2 receptor antagonist, kidney transplantation, monoclonal antibody

\section{Introduction}

Acute rejection episodes are one of the risk factors of developing chronic allograft injury and significantly reduce the long-term survival rates. ${ }^{1-3}$ New and more potent immunosuppressive medications have reduced incidence of acute rejection and improved short-term graft survival, but they have not greatly enhanced long-term outcomes. One of the reasons for this observation may be the adverse effects of immunosuppressive medication that may contribute to graft dysfunction as well as mortality and morbidity of transplant patients; eg, calcineurin inhibitors (CNIs) cause acute and chronic nephrotoxicity and corticosteroids increase cardiovascular and other risk factors. ${ }^{4,5}$ Immunosuppression agents can also be associated with infections and malignancies, which affect long-term patient survival. ${ }^{6}$

Because interleukin-2 (IL-2) plays a critical role in T-cell activation and proliferation, antibodies against $\alpha$ subunit (CD25) of IL-2 receptor (IL-2R) have been tested in animal and human models. ${ }^{7-9}$ Murine monoclonal antibodies to CD25 significantly reduce acute rejection episodes, but the high immunogenicity and short half-life of these antibodies limited their clinical use. ${ }^{7,10}$ To overcome these problems, 
chimeric (basiliximab) and humanized (daclizumab) murine antibodies to CD25 have been developed. These agents have a high affinity and specificity for CD25 on the surface of activated T-cells and inhibit IL-2-mediated activation and proliferation of T-cells in transplant patients, aiming at a low acute rejection rate without affecting the pre-existing immune responses.

In this article we review the studies using anti-IL-2R antibody (IL-2RA) induction in renal transplantation, emphasizing the prevention of acute rejection in different protocols. We also examined the efficacy and safety of IL-2RA in combination with a reduction or avoidance of corticosteroids and CNIs, and compared IL-2RAs with lymphocyte-depleting monoclonal and polyclonal antibodies for induction therapy. Studies using IL-2RA for treatment of established rejection episodes are not included in this review.

\section{Dosage regimens and pharmacological properties}

In phase III studies, two doses of basiliximab (20 mg each) were given on day 0 and day $4,{ }^{11,12}$ which saturates IL-2 $\mathrm{R} \alpha$ on the circulating lymphocytes for 4-6 weeks. Because of poor correlations between body weight and distribution volume or clearance, weight-adjusted dosing is not recommended for basiliximab. ${ }^{13,14}$ Dosage modification is required for pediatric patients weighing $<35 \mathrm{~kg}$, who should receive two doses of $10 \mathrm{mg}$ each. ${ }^{15}$ On the contrary, phase III studies of daclizumab was conducted with a bodyweight-adjusted dose: $1 \mathrm{mg} / \mathrm{kg}$ once every two weeks for a total of five doses with cyclosporine (CsA)based triple ${ }^{16}$ or dual ${ }^{17}$ maintenance immunosuppression; this suppresses IL-2R for up to four months after renal transplantation. ${ }^{16}$ Subsequently, limited doses regimens (mainly two doses, at the time of transplant and 10-14 days thereafter) were tested with concomitant use of more potent baseline immunosuppression (eg, tacrolimus [TAC] and/or mycophenolate mofetil [MMF]). ${ }^{18-21}$ Two doses of daclizumab were shown to be sufficient to block IL-2R $\alpha$ for more than 10 weeks. ${ }^{19}$ A smaller study demonstrated one dose (2 mg/kg on day 0$)$ and two doses $(2 \mathrm{mg} / \mathrm{kg}$ on day 0 and $1 \mathrm{mg} / \mathrm{kg}$ on day 14) of daclizumab saturates the IL-2R $\alpha$ on the circulating lymphocytes for up to 42 days and 70 days, respectively. ${ }^{20}$

Because $90 \%$ of daclizumab and $75 \%$ of basiliximab are human immunoglobulin $\mathrm{G}$ (IgG), pharmacokinetic parameters are similar to exogenous human IgG antibodies. Both basiliximab and daclizumab have a small volume distribution in the central component $(2.5-5.0 \mathrm{~L})$, and exhibit a low total body clearance $(10-40 \mathrm{~mL} / \mathrm{hr})$. Unlike murine monoclonal antibodies, both chimeric and humanized antibodies have prolonged serum half-lives, seven days for basiliximab and 20 days for daclizumab, in adult renal transplant patients. ${ }^{13-16,20,22,23}$ Limited data suggest drug interaction and pharmacokinetic alteration with CsA, TAC, azathioprine, and MMF. ${ }^{24-26}$ Anti-idiotypic antibody development against the murine portion of these antibodies are rare owing to low immunogenicity. ${ }^{22,27}$

\section{IL-2RA with CsA-based dual or triple therapy}

Following phase I/II studies by Amlot and Kovarik and colleagues, ${ }^{13,27}$ the clinical efficacy and safety of basiliximab induction were evaluated with baseline immunosuppression consisting of cyclosporine microemulsion (CsA-ME) and steroids in two randomized, double-blind, placebo-controlled multicenter phase III trials. ${ }^{11,12}$ International Study Group (Europe/Canada) demonstrated significant reduction of clinical and biopsy-proven acute rejection (BPAR) six months after deceased donor kidney transplantation (34\% vs 52\%, $P<0.001$ and $30 \%$ vs $44 \%, P=0.012$, respectively). ${ }^{11}$ The incidence of steroid-resistant first rejection episodes that required antibody therapy was also significantly lower in the basiliximab group ( $10 \%$ vs $23 \%, P<0.001)$. The incidence of infection and other adverse events was similar in the two treatment groups. The acute tolerability of basiliximab was excellent, with no evidence of cytokine-release syndrome. A US trial of living or deceased donor kidney transplantation complied with these findings, showing significant reduction of rejection episodes: $38 \%$ vs 55\% $(P=0.001)$ for clinical rejection and $35 \%$ vs $49 \%(P=0.009)$ for BPAR at 12 months. ${ }^{12}$ The rates of infection and other adverse events were similar. In both trials, the amount of steroids required was significantly lower in patients treated with basiliximab than in patients treated with placebo $(0.56 \mathrm{vs} 0.93 \mathrm{mg} / \mathrm{kg} / \mathrm{day}$, $P<0.001^{11}$ and 0.59 vs $0.78 \mathrm{mg} / \mathrm{kg} / \mathrm{day}, P=0.02,{ }^{12}$ both at four weeks post-transplant). Of note, only the US trial demonstrated better renal function at 1-12 months in patients treated with basiliximab. Patient and graft survival rates were not significantly different although the studies were not powered to detect small differences. In a pooled analysis of these two phase III trials, not only a significant reduction of acute rejection (by $44 \%, P<0.01$ ) but also superior graft survival (96\% vs $85 \%, P=0.022)$ were evident in diabetic subpopulation at one-year post-transplant with comparable safety profile. ${ }^{28}$ 
Combination of basiliximab and triple maintenance therapy (CsA-ME/ azathioprine/ steroids) was also evaluated in a randomized multicenter study. ${ }^{29}$ During the first six months post-transplant, clinical acute rejection and BPAR occurred in 21\%/19\% of patients given basiliximab vs $35 \% / 29 \%$ of patients administered placebo $(P=0.005)$. Basiliximab, however, did not decrease the severity of rejection or rate of steroid-resistant rejection. The incidence of infections including cytomegalovirus (CMV) infections and other side effects were indistinguishable between patients given basiliximab and placebo. One-year patient and graft survival was similar in two groups.

Vincenti and colleagues reported the first clinical trial of daclizumab with excellent tolerability and safety, ${ }^{22}$ which prompted two phase III, randomized, placebo-controlled clinical trials. ${ }^{16,17}$ There were a total of 535 recipients of first deceased donor renal transplants randomized to receive five doses of daclizumab or placebo. In the first study, 126 daclizumab-treated recipients and 134 placebo-treated recipients received CsA, azathioprine, and steroids. ${ }^{16}$ The second study was otherwise identical (daclizumab $=116$ patients, and placebo $=111$ patients), but concurrent immunosuppression consisted of only CsA and steroids (dual therapy). ${ }^{17}$ In both studies, the addition of daclizumab significantly reduced the rate of BPAR (primary efficacy end-point) as compared with the placebo. At six months, the BPAR rate in patients treated with daclizumab was $22 \%$ vs $35 \%$ in those given placebo with triple therapy $(P=0.03),{ }^{16}$ and $28 \%$ vs $47 \%$ with dual therapy $(P=0.001) .{ }^{17}$ The graft survival rates after one year tended to be higher in daclizumab-treated recipients in the first study ( $95 \%$ vs $90 \%, P=0.08)$. The second study demonstrated better patient survival ( $99 \%$ vs $94 \%, P=0.01$ ), although the patient and graft survival of placebo patients in this study seemed to be lower than placebo patients in other phase III trials evaluating IL-2RA. ${ }^{17}$ The graft function was also better in daclizumab-treated patients ( $58 \mathrm{vs} 51 \mathrm{~mL} / \mathrm{min}, P=0.02$ ). Daclizumab was not associated with a higher incidence of infectious complications or cancers. Pooled analyses of these two studies demonstrated less frequent BPAR at one-year in daclizumab-treated patients as compared with placebotreated patients $(28 \%$ vs $43 \%, P<0.01,36 \%$ reduction by daclizumab). ${ }^{30,31}$ This was not accompanied by improved graft survival at three years ( $84 \%$ vs $83 \%$ for triple therapy and $82 \%$ vs $78 \%$ for dual therapy), while the trials were inadequately powered to detect differences. The pooled three-year patient survival rate in the dual- and triple-therapy trials was $93 \%$ in daclizumab- and $91 \%$ in placebo-treated patients (not significant [NS]). The incidence of malignancies or post-transplant lymphoproliferative disorder at three years in daclizumab and placebo patients was comparable in both clinical trials.

A meta-analysis of IL-2RA, including anti-Tac (murine IgG2a IL-2RA), BT563 (murine IgG1 IL-2RA), basiliximab, and daclizumab, has reported that treatment with IL-2RA was associated with a significant reduction in the risk of acute rejection at six months (odds ratio [OR] 0.51; 95\% confidence interval $[\mathrm{CI}]: 0.42$ to $0.63 ; P<0.0001) .{ }^{32}$ The effect on acute rejection was similar for different types of IL-2RA: basiliximab (OR $0.56,95 \%$ CI: 0.44 to 0.72 ; $P<0.0001$ ) and daclizumab (OR $0.46,95 \%$ CI: 0.32 to 0.67 ; $P<0.0001)$. The test for heterogenicity between antibody groups was not significant $(P=0.7)$. The reduction in acute rejection was also similar for triple and dual immunosuppression regimens. There were no significant differences in the rate of graft loss, mortality, incidence of infections, or risk of malignancies at one year.

In summary, adding basiliximab or daclizumab to CsA-based dual or triple therapy reduces incidence of acute rejection without significant increase in infection or malignancy, although these initial trials evaluated IL-2RAs mainly on low-immunological-risk patients. The effect of IL-2RA on graft and patient survival was not fully validated and waits further evaluation.

\section{IL-2RA with MMF and/or TAC}

In concert with the introduction of newer and more potent maintenance immunosuppressive medication, basiliximab and daclizumab were evaluated in different immunosuppressive protocols..$^{26,33-38}$ In a short report of a blind randomized trial, 75 patients treated with maintenance immunosuppression consisting of CsA, MMF, and steroids were administered daclizumab or placebo. ${ }^{39}$ There was a six-month BPAR rate of $12 \%$ in daclizumab-treated patients as compared with $20 \%$ in those receiving placebo. The combination of daclizumab and maintenance triple therapy with MMF was safe, well tolerated, and demonstrated low incidence of acute rejection. In another nonrandomized trial evaluating the combination of daclizumab with MMF/steroids/CNI (CsA-ME or TAC), Iverson and colleagues compared 58 patients (64\% Hispanic) who received living donor renal allografts with a matched cohort of 27 patients. ${ }^{33}$ The four-month BPAR rate was 7\% in daclizumab-treated patients vs $15 \%$ in control patients. There were no differences in the rate of adverse events, graft, and patient survival.

Lawen and colleagues randomized low-to-standard risk kidney transplant recipients to basiliximab $(n=59)$ and 
placebo $(n=64)$ in addition to CsA-ME, MMF, and steroids in a multicenter, double-blind, placebo-controlled study. ${ }^{40}$ Tolerability of basiliximab (the primary end point) was equivalent to placebo, with no increase in serious adverse events, infection, malignancy, or post-transplant lymphoproliferative disorder. At six months, while not powered to demonstrate a statistical significance, there were trends in favor of basiliximab over placebo in the incidence of first BPAR ( $15 \%$ vs $27 \%, P=0.18)$ and of acute rejection treated with antibody ( $5 \%$ vs $16 \%, P=0.08)$. There was also a trend to lower delayed graft function (DGF) and to improve graft function more rapidly in the basiliximab group than in the placebo-treated group.

A meta-analysis from the Cochrane Library included 117 reports from 38 randomized trials utilizing IL-2RA in renal transplantation. ${ }^{41}$ Of those trials, 17 compared IL-2RA (10 basiliximab, 4 daclizumab, and 3 others) with placebo or no treatment, whereas 15 compared IL-2RA ( 9 basiliximab, 3 daclizumab, and 3 others) with other induction therapy (11 polyclonal antilymphocyte/thymocyte antibodies and 4 muromonab CD3). The majority of trials used CsA (31 CsA and 7 TAC) and MMF (23 MMF and 16 azathioprine). Acute rejection was significantly reduced at six months (relative risk [RR], 0.66, 95\% CI: 0.59-0.74) and 12 months (RR, 0.67, 95\% CI: 0.60-0.75) when IL-2RAs were compared with placebo. Graft loss, death, CMV infection, malignancy, and DGF all favored the use of IL-2RA, but none reached statistical significance because of lack of power. When added to standard dual or triple therapy, IL-2RA reduced the risk of clinically diagnosed acute rejection by $34 \%$ and the risk of steroid-resistant rejection by $49 \%$ as compared with noninduction therapy. ${ }^{41}$

TAC and MMF are often combined with more practical and cost-effective limited doses of daclizumab induction as opposed to the recommended five-dose regimen. ${ }^{18-20}$ A multicenter study utilizing two doses of daclizumab on day 0 and day 10 post-transplant in 40 adult renal transplant recipients, in combination with TAC and MMF, demonstrated a BPAR rate of $13 \%$ during a median follow-up period of 29 weeks. ${ }^{19}$ Ahsan and colleagues reported a prospective study comparing a single intraoperative dose of daclizumab (2 mg/kg, $\mathrm{n}=50)$ vs noninduction $(\mathrm{n}=50)$ in first low-immunological-risk kidney transplant patients treated with TAC, MMF, and prednisone. ${ }^{18}$ During the first six months, episodes of first BPAR were 3/50 (6\%) in the limited daclizumab group and 8/50 (16\%) in the control group $(P<0.05)$. Twelve-month patient and graft survival were not statistically different (100\% vs $98 \%$ and $100 \%$ vs $94 \%$, respectively). These studies suggest that a limited dose of daclizumab when combined with a CNI, MMF, and steroids are sufficient for patients at low immunological risk to reduce early renal allograft rejection without adverse effects, and without the need for a more prolonged course of daclizumab as originally recommended.

\section{IL-2RA in high-immunological-risk patients}

While majority of patients enrolled in randomized trials has low-to-standard immunological risk, IL-2RAs have been used with MMF and either CsA or TAC to reduce acute rejection in high-immunological-risk patients (Table 1)..$^{42-45}$ Meier-Kriesche reported 29 black and 20 Hispanic renal transplant recipients treated with daclizumab ( $1 \mathrm{mg} / \mathrm{kg} \times$ five doses $), \mathrm{CsA}, \mathrm{MMF}$, and steroids, and compared with simultaneous cohort of 31 black and 25 Hispanic patients receiving the same immunosuppression without daclizumab induction therapy. ${ }^{44}$ Acute rejection rates were lower in the daclizumab group than in the control group ( $26 \%$ vs $49 \%$ per patient years, respectively). A total of eight recurrent rejections in six patients occurred in the control group and none in the daclizumab arm. In another single center study, Ciancio and colleagues compared racial differences in incidence of BPAR among black $(\mathrm{n}=37)$, Hispanic $(n=85)$, and Caucasian $(n=111)$ first renal transplant recipients using daclizumab $(1 \mathrm{mg} / \mathrm{kg} \times$ five doses $)$, TAC, MMF, and steroids. ${ }^{42}$ BPAR rate at one-year was $8.1 \%$ in black, $4.7 \%$ in Hispanic, and $4.5 \%$ in the Caucasian group $(P=0.7)$. Graft and patient survival as well as renal function were comparable. Ciancio and colleagues also reported the use of daclizumab with TAC, MMF, and steroids in renal transplant recipients with previous transplants: 4 previous liver, 15 previous kidney, and 3 previous pancreas/kidney. ${ }^{46}$ The incidence of BPAR was $0 \%, 13 \%$, and $0 \%$ for previous liver, kidney, pancreas/kidney recipients, respectively. Few complications have occurred without CMV infection. These studies demonstrated the efficacy and safety of combining daclizumab, CNI, MMF, and steroids in highimmunological-risk patients.

\section{IL-2RA in CNI-sparing protocols}

Because CNIs have intrinsic acute and chronic nephrotoxicity, IL-2RAs have been assessed for the potential addition to CNI-avoidance or -withdrawal after kidney transplantation (Table 2). The goal of this strategy is to maintain adequate renal function without increasing incidence of acute rejection. 
Table I Immunological risk status

\begin{tabular}{|c|c|c|c|c|c|c|c|}
\hline Population risk status & Race & Transplant type & PRA & HLA mismatch & Donor type & CIT & DGF \\
\hline Low & Caucasian & Primary & PRA $<10 \%$ & 0 & Living related donor & $<18$ hours & No \\
\hline \multicolumn{8}{|l|}{ Standard } \\
\hline \multirow[t]{5}{*}{ High } & Black & Repeat & PRA $>80 \%$ & 6 & Expanded criteria & $>36$ & Yes \\
\hline & & transplant with & & & donor & hours & \\
\hline & & immunological & & & Donor after cardiac & & \\
\hline & & loss of a & & & death & & \\
\hline & & previous allograft & & & (Deceased donor) & & \\
\hline
\end{tabular}

Notes: Patients are often categorized as "low risk" or "high risk" when some of the above criteria are met; "standard risk" are in between "high risk" and "low risk", but actual definition may vary in each study.

Abbreviations: CIT, cold ischemia time; DGF, delayed graft function; HLA, human leukocyte antigen; PRA: panel reactive antibody.

\section{$\mathrm{CNI}$ avoidance and withdrawal}

Two noncomparative studies reported complete avoidance of CNIs from the immunosuppressive protocol. In a multicenter trial reported by Vincenti and colleagues, 98 recipients of primary deceased or living donor kidneys at low immunological risk received daclizumab $(2 \mathrm{mg} / \mathrm{kg}$ for the first dose and $1 \mathrm{mg} / \mathrm{kg}$ for the subsequent four doses), MMF ( $3 \mathrm{~g} /$ day for the first six months and $2 \mathrm{~g} /$ day thereafter), and corticosteroids. ${ }^{47}$ BPAR was diagnosed in $48 \%$ of patients during the first six months and in $53 \%$ by 12 months after transplantation. At one-year post-transplant, $62 \%$ of patients had received CNI for more than seven days, predominantly because of rejection.

In a single-center study, Tran and colleagues used the similar protocol for 45 renal transplant recipients including 12 black patients. ${ }^{48}$ The incidence of BPAR was $31 \%$ and occurred early in deceased donor transplant (median, 7 days); $51 \%$ of the patients required the addition of CsA maintenance. Although theses studies provided benefits to a sizable minority of patients who have not required chronic CNI therapy with better renal function, the long-term results remain to be evaluated considering high incidence of acute rejection using this strategy.

The Cyclosporine Avoidance Eliminates Serious Adverse Renal-toxicity (CAESAR) trial compared CsA withdrawal $(\mathrm{n}=179)$ and low-dose CsA $(\mathrm{n}=183)$ with standard-dose CsA $(n=173)$ in low-immunological-risk recipients, all in combination with MMF ( $2 \mathrm{~g} /$ day) and steroids, but only withdrawal and minimization groups received daclizumab induction $(2 \mathrm{mg} / \mathrm{kg}$ before transplant followed by four more doses of $1 \mathrm{mg} / \mathrm{kg}$ ). ${ }^{49}$ The primary end point of the study (renal function at 12 months) was not statistically different (glomerular filtration ratio [GFR] $51 \mathrm{~mL} / \mathrm{min} / 1.73 \mathrm{~m}^{2}$ in CsA withdrawal group and low-dose CsA group, and $49 \mathrm{~mL} / \mathrm{min} / 1.73 \mathrm{~m}^{2}$ in standard-dose CsA group). By withdrawing CsA at six months after transplant, the patients experienced higher incidence of BPAR, as compared with low-dose CsA and standard-dose CsA patients ( $38 \%$ vs $25 \%$ vs $28 \%$, respectively, $P<0.05$ ). From this large-scale trial, it may be concluded that low-dose CsA is better than total withdrawal of CsA when combined with daclizumab induction, MMF, and steroids.

\section{CNI sparing with $\mathrm{mTOR}$ inhibitors}

IL-2RA has also been combined with long-term use of mammalian target of rapamycin (mTOR) inhibitors (sirolimus [SRL] or everolimus) in lieu of CNIs or in addition to low-dose CNIs. Flechner and colleagues reported five-year outcomes of 61 low-to-standard risk patients randomized to SRL (target trough level 10-12 $\mathrm{ng} / \mathrm{ml}$ for six months and 5-10 ng/ml thereafter) or CsA (target trough level $200 \mathrm{ng} / \mathrm{ml}$ for one year and 150-170 $\mathrm{ng} / \mathrm{ml}$ thereafter) after basiliximab induction and MMF with steroids..$^{50,51}$ SRL-treated patients compared with CsA-treated patients demonstrated similar patient survival (87\% vs $90 \%$ ) and acute rejection rates (13\% vs $23 \%)$, respectively. In SRL-treated patients, death-censored graft survival rate was higher $(96 \%$ vs $77 \%, P=0.027$ ) and GFR was higher (67 vs $51 \mathrm{~mL} / \mathrm{min}$, $P=0.008)$ with similar urine protein and serum cholesterol levels. Martinez-Mier and colleagues used a similar protocol for 41 living related kidney transplants in a single center randomized trial, showing comparable patient and graft survival. ${ }^{52}$ Although the rejection rate was numerically high in SRL-treated patients ( $17 \%$ vs 5\%, NS), none of the patients who had target SRL levels suffered acute rejection at one year.

The Efficacy Limiting Toxicity Elimination (ELITE)Symphony study is a prospective, randomized, open-label, multicenter trial comparing four parallel groups of adult renal transplant recipients..$^{53}$ Low-immunological-risk patients were randomly assigned to standard-dose CsA 


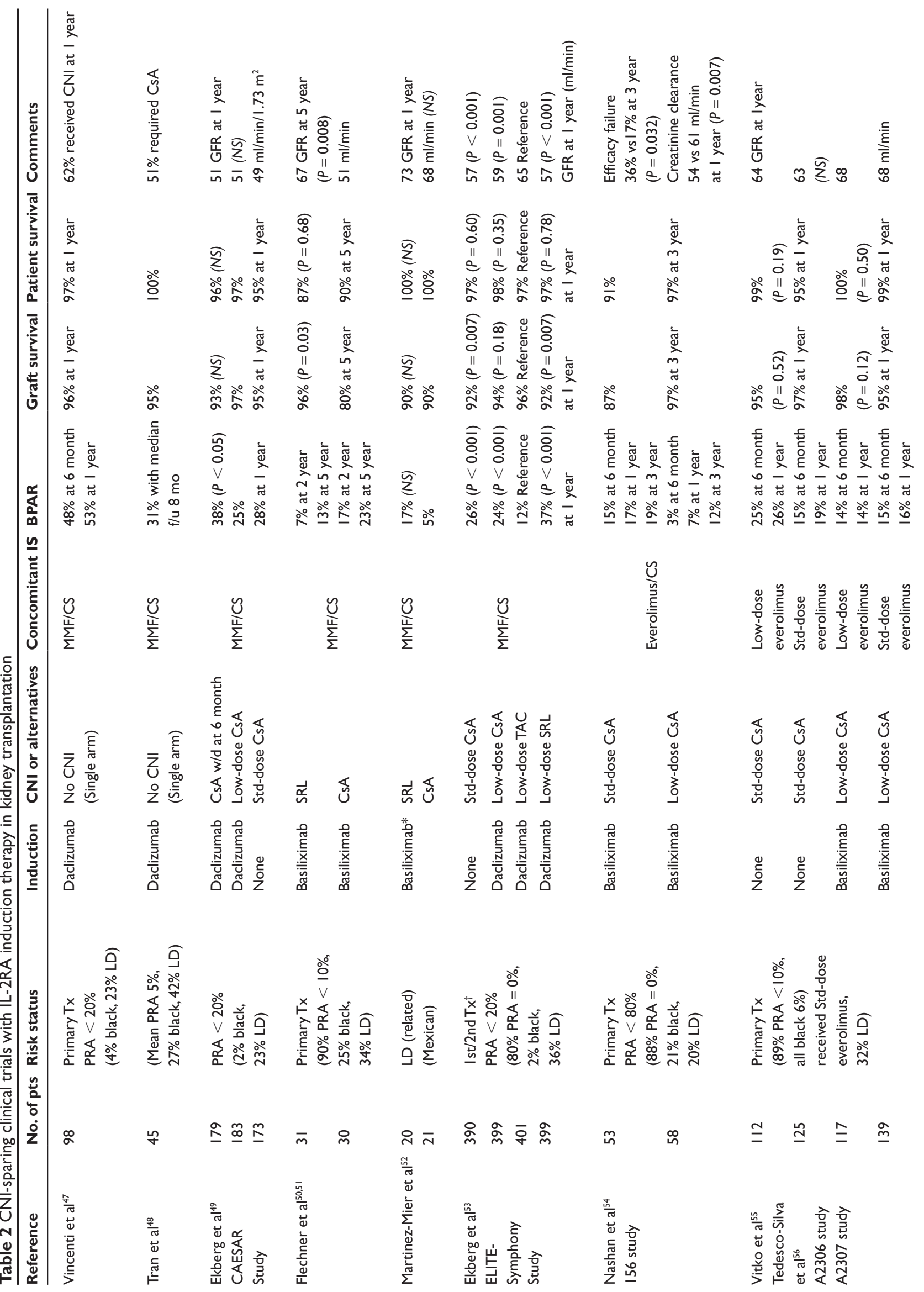


( $\mathrm{n}=390$, target trough level, $150-300 \mathrm{ng} / \mathrm{ml}$ for three months and $100-200 \mathrm{ng} / \mathrm{ml}$ thereafter), low-dose CsA ( $\mathrm{n}=399$, target trough level, $50-100 \mathrm{ng} / \mathrm{ml})$, low-dose TAC $(\mathrm{n}=401$, target trough level, 3-7 ng/ml), or low-dose SRL ( $\mathrm{n}=399$, target trough level, $4-8 \mathrm{ng} / \mathrm{ml}$ ). All groups received MMF ( $2 \mathrm{~g} /$ day) and corticosteroids. Daclizumab ( $2 \mathrm{mg} / \mathrm{kg}$ before transplant followed by four more doses of $1 \mathrm{mg} / \mathrm{kg}$ ) was given to all but the standard-dose CsA group. Estimated GFR at one year (the primary end point) was significantly higher in the low-dose TAC group ( $65 \mathrm{~mL} / \mathrm{min})$ than in the other three groups (57-59 $\mathrm{mL} / \mathrm{min}, P<0.001)$. BPAR rate at one year was lower in the low-dose TAC group (12.3\%) than in the other three groups (standard-dose CsA 25.8\%, low-dose CsA $24.0 \%$, low-dose SRL 37.2\%; $P<0.001$ ). Death-censored allograft survival was higher in the low-dose TAC group (96\%) than in the standard-dose CsA and the low-dose SRL groups (both $92 \% ; P=0.007$ ). Serious adverse events were observed in 53\% of patients in the low-dose SRL group, as compared with $43 \%-44 \%$ in the other groups $(P<0.05)$. Based on the results above, when daclizumab is combined with low-dose TAC, outcomes seem to be better than standard CsA-MMF-steroid-based regimen without induction therapy; however, when daclizumab is combined with low-dose SRL without CNIs, outcomes seem to be worse than the standard triple regimen.

Low-dose CNI with mTOR inhibitor has been tested in other studies. Nashan and colleagues compared full-dose CsA ( $\mathrm{n}=53$, trough level, $125-250 \mathrm{ng} / \mathrm{ml})$ and reduced-dose CsA ( $\mathrm{n}=58$, trough level, $50-100 \mathrm{ng} / \mathrm{ml}$ ) in combination with basiliximab, everolimus ( $3 \mathrm{mg}$ /day) and steroids in a randomized, multicenter, open-label study (156 study) of low-to-standard risk patients. ${ }^{54}$ In the reduced-dose CsA group, a lower incidence of BPAR (3\% vs $15 \%$ at six months and $7 \%$ vs $17 \%$ at one year) was accompanied by higher mean creatinine clearance $(61 \mathrm{vs} 54 \mathrm{~mL} / \mathrm{min}$ at one year, $P<0.007)$ and less frequent discontinuations and serious adverse events. Vitko and colleagues and Tedesco-Silva and colleagues reported six- and 12-months safety and efficacy results of two randomized studies (A2306 and A2307) of low-to-standard risk patients using the similar immunosuppressive medication. ${ }^{55,56}$ Study $1(\mathrm{~A} 2306, \mathrm{n}=237)$ had no induction therapy; in Study $2(\mathrm{~A} 2307, \mathrm{n}=256)$ basiliximab was administered. These studies compared two different doses of everolimus ( $1.5 \mathrm{vs} 3 \mathrm{mg} /$ day) with steroids and reduced-dose CsA (initial CsA $\mathrm{C}_{2}$ target $1200 \mathrm{ng} / \mathrm{ml}$ for Study 1 and $600 \mathrm{ng} / \mathrm{ml}$ for Study 2 with subsequent tapering to $400 \mathrm{ng} / \mathrm{ml}$ for both studies). As black patients have a higher everolimus clearance rate than Caucasian patients, all black 
subjects received $3 \mathrm{mg} /$ day everolimus. These regimens were well tolerated and preserved renal function throughout the study, with no differences observed between groups within studies. Without basiliximab induction, there was a trend towards a reduction in the incidence of BPAR among nonblack randomized to $3 \mathrm{mg}$ /day everolimus as compared with $1.5 \mathrm{mg} /$ day everolimus (16\% and $26 \%$ at 12 months, respectively; $P=0.08$ ). The inclusion of basiliximab lowered the overall incidence of acute rejection $(15 \%$ for $3 \mathrm{mg} / \mathrm{dl}$ and $14 \%$ for $1.5 \mathrm{mg} / \mathrm{dl}$ at six months; $16 \%$ vs $14 \%$ at 12 months).

\section{Delayed $\mathrm{CNI}$ introduction}

As designed in phase I/II studies, the other potential use of IL-2RA induction is to delay introduction of CNIs to prevent acute nephrotoxicity while the transplanted kidney has delayed or slow graft function. ${ }^{13}$ Small studies reported initial CNI avoidance with a combination of daclizumab/ basiliximab, SRL, and steroids. This regimen provided reasonable acute rejection prophylaxis in 43 kidney recipients (acute rejection rate 16\%). ${ }^{57}$ In a retrospective analysis of 14 patients, Chang and colleagues added MMF to this regimen, resulting in an acute rejection rate of $14 \%$ and graft survival rate of $100 \%$ during the follow-up period of 0.5-5.2 months. ${ }^{37}$ Although SRL may prolong recovery from DGF, ${ }^{58}$ the ability of IL-2RA to protect kidneys from acute rejection with excellent safety profile makes this strategy attractive. Moreover, it has been suggested that use of an IL-2RA may decrease the risk of delayed or slow graft function. ${ }^{12,59,60}$

The French Myeariade FR01 study group evaluated early and delayed CsA in a 12-month, prospective, randomized, open-label study of de novo low-risk renal transplant patients. ${ }^{61,62}$ CsA-ME at an initial dose of $8 \mathrm{mg} / \mathrm{kg} / \mathrm{dose}$ was started either on day $0(n=97)$ or day $6(n=100)$ post-transplant, and dose adjusted according to $\mathrm{C}_{2}$ level. All patients received enteric-coated mycophenolate sodium, steroids, and either two doses of basiliximab or five doses of daclizumab. One-third of patients in both groups had a DGF Risk Index Score of $\geq 5$ (US Renal Data System). The incidence of BPAR was numerically high (26\% vs $16 \% ; P=0.11$ ) at 12 months in the delayed CsA-ME group as compared with the early CsA-ME group, although the study was not powered to detect differences. Early or delayed introduction of CsA-ME did not affect renal function $(51 \mathrm{ml} / \mathrm{min}$ vs $54 \mathrm{ml} / \mathrm{min}$ at three months; $P=0.43$ ) or DGF rate $(27 \%$ vs $23 \%$;S). The extension of this study with a mean follow up of 30 months demonstrated comparable creatinine clearance between groups. NI2A Study Group in Spain also compared different patterns of CsA initiation in renal transplant recipient from expanded criteria donors and high risk of DGF: early low-dose CsA ( $3 \mathrm{mg} / \mathrm{kg} /$ day, $\mathrm{n}=38)$, early standard-dose CsA ( $5 \mathrm{mg} / \mathrm{kg} /$ day, $\mathrm{n}=40)$, and delayed standard-dose CsA ( $5 \mathrm{mg} / \mathrm{kg} /$ day $7-10$ days after transplant, $\mathrm{n}=36) .{ }^{63}$ This multicenter six-month, open-label, randomized trial with basiliximab, MMF, and steroids revealed no differences among groups in six months GFR, DGF rate $(31 \%, 38 \%$, and $42 \%$ for early low-dose CsA, early standard-dose CsA, delayed standard-dose CsA, respectively), and $\mathrm{BPAR}$ rate $(5 \%, 13 \%$, and $11 \%)$, although combined clinically treated and BPAR rate was significantly higher in the delayed CsA group (5\%,15\%, and 25\%). These results suggest delayed introduction of CNIs with IL-2RA, $\mathrm{MMF}$, and steroids does not improve renal function or lower DGF rate; it may increase acute rejection episodes.

In summary, results of CNI sparing protocols have been mixed. Minimization of CNIs may be associated with improved renal function; however, CNI avoidance or withdrawal often increases risk of acute rejection. Further study is needed to determine whether the short-term benefit of CNI minimization translates into long-term improvement of graft and patient survival with alternative immunosuppressive medication including IL-2RA induction and mTOR inhibitors.

\section{IL-2RA in corticosteroid sparing protocols}

Corticosteroids have been a mainstay of immunosuppression for several decades despite their major adverse effects: hypertension, diabetes, dyslipidemia, bone loss, avascular necrosis, weight gain, cataracts, and psychotic behavior. Although these side effects may increase mortality and morbidity after transplantation, steroid withdrawal has been associated with high rejection rate and poor graft survival. ${ }^{64-67}$ To prevent rejection early post-transplant, antibody induction including IL-2RA has been utilized in steroid-sparing protocols (Table 3 ).

\section{Steroid withdrawal with CNIs and MMF}

A pilot study by Cole and colleagues introduced daclizumab and MMF to a CsA-based immunosuppressive protocol to avoid steroid use. Sixty-five percent of patients remained steroid-free with acute rejection rate of $25 \%$, suggesting this as a practical strategy. ${ }^{68}$ Vincenti and colleagues randomized 84 low-to-standard risk primary renal transplant recipients receiving basiliximab, $\mathrm{CsA}-\mathrm{ME}$, and $\mathrm{MMF}$ to 
either corticosteroid withdrawal at day 4 post-transplant or standard steroid therapy. ${ }^{69}$ The incidence of BPAR at 12 months was comparable $(20 \%$ vs $16 \% ; P=0.73)$ with $100 \%$ death-censored graft survival in both groups. The majority $(72 \%)$ of patients remained off steroids, showing feasibility of steroid-withdrawal with basiliximab.

With TAC and MMF-based immuosuppression, ter Meulen and colleagues randomized low-to-high risk patients to three-day steroids plus two doses of daclizumab (daclizumab group, $\mathrm{n}=186$ ) and four-month steroids (control group, $\mathrm{n}=178) .{ }^{21}$ The incidence of BPAR at 12 months $(15 \%$ vs $14 \%$ ) and graft survival (91\% vs $90 \%$ ) were comparable between the daclizumab and control groups. Mean arterial blood pressure, serum lipids, and incidence of patients with hyperglycemia were temporarily lower in the daclizumab group than controls. The efficacy of daclizumab was also tested in the CARMEN study: an open-label, multicenter, parallel-group study with 538 low-to-standard risk renal patients randomized to a daclizumab/TAC/MMF or a TAC/MMF/corticosteroids. ${ }^{70}$ The patients who received two doses of daclizumab and no steroids demonstrated the same low BPAR rate (17\% in both groups) as compared with controls. The steroid-free patients were found to have reduced incidence of insulin-dependent new-onset diabetes after transplantation $(0.4 \%$ vs $5.4 \% ; P=0.003)$, lower total cholesterol level, and similar renal function. These results suggest daclizumab is as effective at preventing acute rejection after renal transplantation as a standard triple regimen and its safety benefits may help improve the long-term outcome of renal transplant patients.

Parrott and colleagues tested the effectiveness of basiliximab in avoiding addition of steroids to CsA-ME monotherapy. ${ }^{60}$ In the low-to-standard immunological risk patients randomized to receive basiliximab $(\mathrm{n}=52)$ or placebo $(n=56)$, more placebo-treated patients $(73 \%)$ required additional immunosuppression at 12 months than basiliximab-treated patients $(54 \%, P=0.05)$. BPAR episodes were observed more frequently in placebo $(43 \%)$ than in basiliximab (29\%) although it was not statistically significant $(P=0.16)$. These findings suggest the efficacy of basiliximab as compared with placebo in steroid-sparing regiments. However, in the Atlas Study, Vitko and colleagues reported higher incidence of BPAR in steroid-free patients at low-to-standard immunological risk. ${ }^{71}$ Two steroid-free regiments (TAC monotherapy after basiliximab induction and TAC/MMF) had BPAR rate of $26 \%$ and $31 \%$, respectively, as compared with standard triple therapy (TAC/MMF/steroids) of $8 \%(P<0.001)$. Graft and patient survival were similar in all groups as was the renal function at six months. The basiliximab/TAC therapy offered some safety benefits (fewer events of leucopenia, diarrhea, and CMV infection).

Woodle and colleagues for the Astellas Corticosteroid Withdrawal Study Group recently published five-year results of a prospective, randomized, double-blind, placebo-controlled multicenter trial comparing seven-day corticosteroid cessation versus long-term, low-dose corticosteroid therapy. ${ }^{72}$ About one-third of the patients at low risk in each group received either basiliximab or daclizmab, while two-thirds of patients received antithymocyte globulin. Overall, there was no difference in a composite outcome of death, graft loss, or moderate/severe acute rejection (16\% and $14 \%$ in steroid withdrawal group and chronic steroid group, respectively). The BPAR rate at five years was numerically higher $(18 \%$ vs $11 \% ; P=0.06)$ and the Kaplan-Meier analysis of BPAR was significantly higher in the steroid withdrawal group $(P=0.04)$ primarily because of mild, Banff 1A, steroid-sensitive rejection. Of note, subgroup analysis revealed similarly low incidence of BPAR with chronic steroid use in patients induced with antithymocyte globulin (10\%) and IL-2RA (12\%); the incidence of BPAR was numerically higher with IL-2RA $(24 \%)$ than antithymocyte globulin $(14 \%, P=0.09)$ in steroid-withdrawal patients. Corticosteroid withdrawal was associated with improved serum triglycerides, less body weight change, and fewer insulin-dependent new-onset diabetes after transplant.

Another recently published trial using basiliximab is the FREEDOM study, which compared complete steroid avoidance and seven-day steroid withdrawal with standard chronic steroid therapy. ${ }^{73}$ Vincenti and colleagues randomized 336 low-risk renal patients into three treatment groups with CsA-ME, enteric-coated mycophenolate sodium, and basiliximab. The 12-month incidence of BPAR, graft loss, or death of the intent-to-treat population was $36 \%$ in the steroid-free group ( $P<0.01$ vs standard), $30 \%$ in steroid withdrawal (NS vs standard) and $19 \%$ in standard steroids. BPAR was significantly more frequent with steroid free and steroid withdrawal than standard steroids (steroid free $32 \%, P<0.01$; steroid withdrawal $26 \%, P=0.05$; standard steroids $15 \%$ ). GFR at 12 months was similar and investigational groups were not inferior to standard steroids in the observed-case analysis. Favorable outcomes in new-onset diabetes after transplant, dyslipidemia, and weight gain were observed in one or both steroid-minimization groups versus standard steroids. These results suggest steroid withdrawal at one week is more desirable than steroid avoidance 


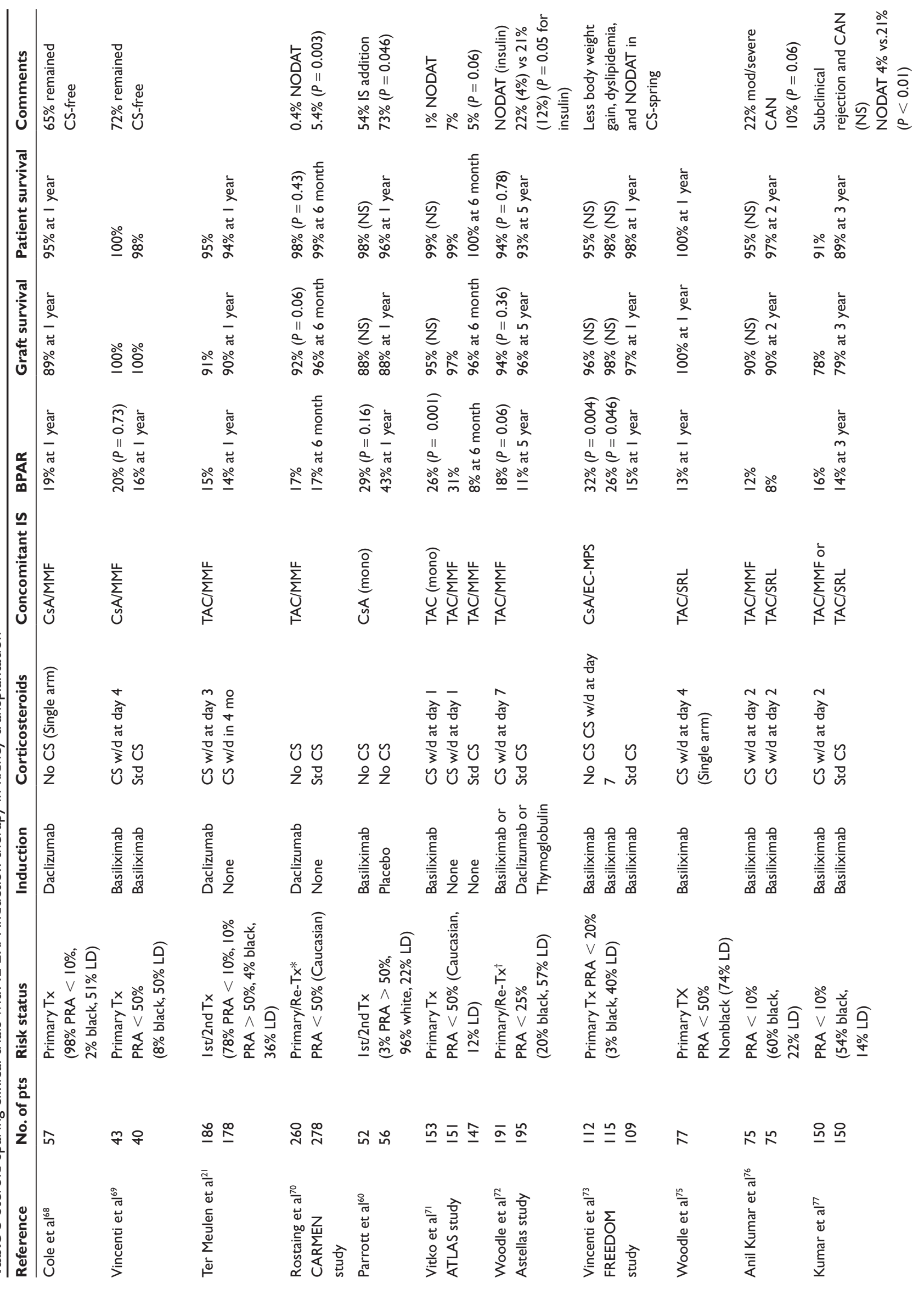




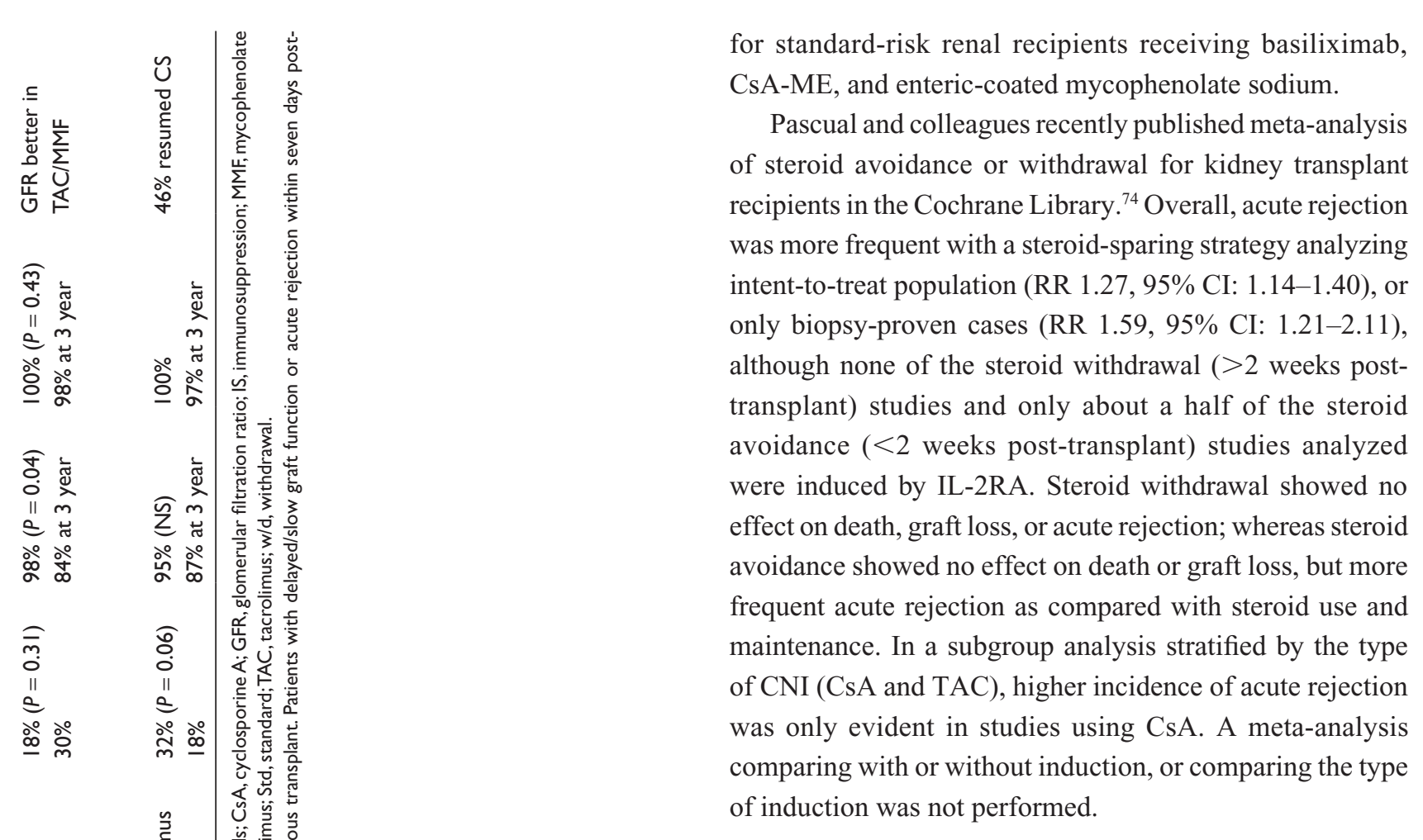

\section{Steroid withdrawal with CNIs and mTOR inhibitors}

IL-2RA induction has been used with mTOR inhibitor-based immunosuppression to minimize steroid use. Woodle and colleagues combined basiliximab, TAC, and SRL in a single arm multicenter pilot study. ${ }^{75}$ Low-risk renal recipients were withdrawn from steroids four days after transplantation and demonstrated excellent one-year patient and graft survival (both $100 \%$ ). BPAR occurred in $13 \%$ and presumptive rejection $11 \%$, with good renal function and safety profile. Anil Kumar and colleagues compared SRL and MMF ( $\mathrm{n}=$ 75 each) in combination with basiliximab, TAC, and twoday steroid ( $60 \%$ black recipients) with surveillance biopsy at $1,6,12$, and 24 months post-transplant. ${ }^{76}$ BPAR was seen in $12 \%$ of TAC/MMF and $8 \%$ of TAC/SRL patients. Surveillance biopsy showed that cumulative incidence of subclinical acute rejection was $27 \%$ in TAC/MMF and $16 \%$ in TAC/SRL groups at two years $(P=0.04)$, and that moderate/severe chronic allograft nephropathy was $22 \%$ and $10 \%$, respectively $(P=0.06)$. Two-year patient and graft survival were equivalent. A comparison of steroid withdrawal and standard steroids of the same investigators showed no increase in BPAR, subclinical acute rejection, or chronic allograft nephropathy; and low incidence of newonset diabetes after transplant ( $4 \%$ vs $21 \%, P<0.01$ ) in the steroid withdrawal group. ${ }^{77}$ In contrast to above studies, Gallon and colleagues reported a single-center analysis of 
low-to-standard risk renal recipients comparing TAC/MMF $(\mathrm{n}=45)$ and TAC/SRL $(\mathrm{n}=37)$ with basiliximab plus two-day steroids. ${ }^{78}$ During the three-year follow-up, graft survival was significantly better in TAC/MMF group (98\%) than in TAC/SRL group $(84 \%, P=0.04)$. Numerically fewer patients experienced BPAR in TAC/MMF $(8 / 45,18 \%$ vs $11 / 37,30 \%, P=0.31)$. Of note, $70 \%$ of the rejection occurred within 30 days post-transplant in both group, suggesting inadequate initial protection by basiliximab.

Utilizing another mTOR inhibitor, Montagnino and colleagues randomized 133 de novo renal transplant recipients at low-to-standard risk to seven-day steroid withdrawal and low-dose chronic steroids with basiliximab, low-dose CsA-ME, and everolimus. ${ }^{79}$ There were more BPAR in steroids withdrawal group $(21 / 65,32 \%)$ than in the low-dose steroid group $(12 / 68,18 \%, P=0.06)$. Graft survival was paradoxically high in steroid withdrawal group (95\% vs $87 \%$, NS) but only $54 \%$ of the patients were steroid-free at three years after transplant: 17 resumed steroids because of acute rejection and 13 were never withdrawn from steroids because of slow graft function. Larger randomized studies are needed to confirm these results and clarify the benefits of steroid withdrawal in CsA-mTOR inhibitor-based immunosuppression.

\section{Steroid withdrawal}

\section{in high-immunological-risk patients}

In high-immunological-risk patients, Alloway and colleagues withdrew steroids from TAC (target trough level, 4-8 ng/ml), SRL (target trough level, $8-12 \mathrm{ng} / \mathrm{ml}$ ), and MMF (2 g/day). ${ }^{80}$ Although initial 10 patients received daclizumab induction ( $2 \mathrm{mg} / \mathrm{kg}$ on days 0 and 14 ), the protocol for the next 15 patients was modified, because of high acute rejection rate, to receive antithymocyte globulin $(1.5 \mathrm{mg} / \mathrm{kg}$ on days 0 and 2) followed by daclizumab on day 14 . Of 25 patients, $40 \%$ were black, $68 \%$ repeated transplant, and $36 \%$ had peak flow PRA $>25 \%$. The incidence of acute rejection was $60 \%$ with daclizumab and $27 \%$ with antithymocyte globulin plus daclizumab. Anil Kumar and colleagues evaluated the safety and efficacy of steroid withdrawal at day 2 post-transplant in black $(n=103)$ as compared with nonblack $(n=103)$ kidney recipients. ${ }^{81}$ Induction was basiliximab and maintenance was CNI (TAC target trough level, 15-18 ng/ml or CsA target C2 level, 1000-1200 ng/ml) plus MMF (2 g/day) or SRL (target trough level, 5-10 ng/ml). Although BPAR rates at one-year were similar $(16 \%$ for black and $13 \%$ for nonblack), the incidence of subclinical acute rejection at one month was higher in the black group than the nonblack group $(23 \%$ vs $11 \% ; P=0.04)$. A five-year follow-up of the study demonstrated still a significant difference of subclinical acute rejection but no difference in clinical BPAR $(16 \%$ vs $14 \%, P=1.0){ }^{82}$ Five-year patient survivals were $81 \%$ and $88 \%(P=0.09)$ and graft survivals were $71 \%$ and $73 \%(P=0.19)$ in the black and nonblack groups, respectively. Prevalence of chronic allograft injury (48\% vs $30 \% ; P=0.05)$, interstitial fibrosis/tubular atrophy $(47 \%$ vs $32 \% ; P=0.05)$, and mean serum creatinine levels ( $2.1 \mathrm{vs}$ $1.8 \mathrm{mg} / \mathrm{dl} ; P=0.05)$ were all higher in the black group.

In summary, early steroid withdrawal in low-to-standard immunological risk patients with IL-2RA induction and CNI-based maintenance therapy is possible with minimal increasing risk of rejection and is probably better than total avoidance of steroids. Steroid-sparing may decrease incidence and severity of steroid-related adverse events; however, long-term benefits of this strategy have not yet been proven.

\section{Comparison of IL-2RA and other antibodies \\ Basiliximab vs daclizumab}

No large-scale randomized study has directly compared two different IL-2RAs. Nair and colleagues reported a small open-labeled prospective study of 23 renal transplant recipients comparing the efficacy of basiliximab (20 $\mathrm{mg}$ on day 0 and day 4 ) and daclizumab ( $1 \mathrm{mg} / \mathrm{kg}$ for five doses) with baseline immunosuppression of CsA, MMF, and steroids. ${ }^{83}$ There was no significant difference in the rate of acute rejection, $10 \%$ with basiliximab and $8 \%$ with daclizumab; time to first rejection episode was eight days with basiliximab versus six weeks with daclizumab. There was no difference in patient and graft survival (100\%) between the two groups at 10 months follow-up. Lin and colleagues randomized 30 patients to basiliximab and 28 patients to daclizumab with CsA, reduced-dose MMF (1 g/day), and steroids. ${ }^{84}$ At six months, the incidence of BPAR was $0 \%$ with basiliximab and $21 \%$ with daclizumab $(P<0.05)$. However, relatively low-dose daclizumab (fixed dose of $50 \mathrm{mg}$ on days 0 and 14) was used in this study as compared with other two-dose regimen studies using total dose of $4 \mathrm{mg} / \mathrm{kg}$. ${ }^{85,86}$ Two meta-analyses of randomized trials utilizing IL-2RA in kidney transplantation demonstrated a similar effect on acute rejection for basiliximab and daclizumab: OR 0.56 vs 0.46 in the first study and RR 0.67 vs 0.66 in the second study. ${ }^{32,41}$

\section{IL-2RA vs muromonab CD3}

Ciancio and colleagues retrospectively compared first kidney transplant patients with daclizumab induction $(n=233)$ and 
muromonab CD3 (OKT3) induction $(\mathrm{n}=225) \cdot{ }^{87}$ Daclizumab was administered in standard five doses $(1 \mathrm{mg} / \mathrm{kg}$ every other week) and muromonab CD3 7-14 doses (5 mg daily) with delayed (2-3 days) TAC, MMF, and steroids. At six months, the BPAR rate was significantly lower in daclizumab-treated patients $(2 \%)$ than in muromonab CD3-treated patients (7\%, $P=0.01)$. One-year patient and graft survival for the daclizumab group was $98 \%$ and $96 \%$ vs $96 \%$ and $94 \%$ for the muromonab CD3 group, respectively (NS). The incidence of infection requiring hospitalization was lower with daclizumab (7 vs $16 \% ; P<0.004$ ) with a similar trend with $\mathrm{CMV}$ infection ( $2 \%$ vs $4 \% ; P=0.14)$. In an updated report of additional recipients $(\mathrm{n}=305)$, the efficacy and safety of daclizumab was still observed: BPAR rate of 5\% with median follow-up of 27 months and CMV infection in $1.6 \%$ of the patients. ${ }^{88}$ The median length of hospital stay was shorter in the basiliximab group than the muromonab CD3 group (10 vs 13 days; $P=0.0001$ ). A similar observation was reported by Kode and colleagues. ${ }^{89}$ In a single-center study, 100 standard-to-high immunological risk patients who received a first or second kidney graft from deceased donor were treated with two doses of basiliximab, low-dose CsA, MMF, and reduced-dose steroids. A historical control group consisted of 26 patients who received muromonab CD3 (7-14 daily doses), delayed full-dose CsA, MMF, and high-dose steroids. Despite a $40 \%$ reduction in steroids, basiliximab-treated patients had fewer BPAR (basiliximab 14\% vs muromonab CD3 35\%) and required less antilymphocyte antibody therapy. Length-of-stay, number of readmissions, total hospitalization days, and CMV infections were lower in the basiliximab group.

\section{IL-2RA vs antithymocyte globulin}

Sollinger and colleagues compared the safety and efficacy of basiliximab $(n=70)$ and equine antithymocyte globulin (ATGAM; $\mathrm{n}=65$ ) with CsA-ME, MMF, and steroids in low-to-standard risk patients. ${ }^{90}$ At 12 months, the rate of BPAR was $19 \%$ and $20 \%$, respectively, in the basiliximab and antithymocyte globulin groups; graft survival, patient survival, and adverse event profile were similar. Lebranchu and colleagues compared basiliximab plus early CsA-ME ( $\mathrm{n}=50)$ versus rabbit antithymocyte globulin $\left(\right.$ Thymoglobulin $\left.{ }^{\circledR}\right)$ plus delayed CsA-ME $(n=50)$ in low-risk, first, deceased-donor kidney transplant patients; all patients received MMF and steroids. ${ }^{91}$ The incidences of BPAR $(8 \%$ in each group) and treatment failure (14\% in the basiliximab group vs $8 \%$ in the antithymocyte globulin group) were comparable in the two groups. There was a tendency to more
DGF requiring dialysis (14\% vs 6\%) and significantly fewer CMV infections $(12 \%$ vs $38 \% ; P=0.005)$ in the basiliximab group. Another small comparison of low-risk renal patients receiving daclizumab $(\mathrm{n}=10)$ and antithymocyte globulin (Fresenius, $\mathrm{n}=35$ ) indicated comparable efficacy and fewer infectious complications in the daclizumab group. ${ }^{92}$ Kyllonen and colleagues reported five-year results of a single-center study randomizing standard-risk patients to single bolus antithymocyte globulin (Fresenius, $9 \mathrm{mg} / \mathrm{kg}$ over $30 \mathrm{~min}$ before reperfusion), basiliximab (20 $\mathrm{mg}$ before reperfusion and on day 4), and no induction. ${ }^{93}$ All patients received CsA, azathioprine, and steroids, but CsA blood trough level was significantly high in no induction group during the first week post-transplant. BPAR rate was numerically low in two induction groups compared with no induction group (antithymocyte globulin 11\%, basiliximab 12\%, and no induction $21 \%$, NS). Antithymocyte globulin was associated with lower incidence of DGF $(6 \%, 24 \%$, and $16 \%$; $P<0.03)$ and higher incidence of adverse events during infusion (ie, low blood pressure, high airway pressure, and low oxygen saturation). Patient and graft survival was similar at five years except that basiliximab group had higher graft survival than no induction group $(97 \%$ vs $84 \% ; P<0.05)$. In terms of long-term adverse events including CMV infection, there were no statistically significant differences among the three groups.

Two recent open-label, multicenter, randomized studies compared basiliximab and rabbit antithymocyte globulin (Thymoglobulin ${ }^{\circledR}$ ). Mourad and colleagues randomized 105 low-risk renal transplant patients to basiliximab and antithymocyte globulin with delayed CsA-ME, MMF, and steroids. ${ }^{94}$ The incidence of BPAR was comparable (basiliximab $10 \%$ vs antithymocyte globulin $9 \%$ ) as were the graft survival (94\% vs 96\%), patient survival ( $98 \%$ for both studies), DGF rate (29\% vs 30\%), and renal function (mean serum creatinine nadir 163 vs $156 \mu \mathrm{mol} / \mathrm{L})$. However, significantly fewer patients in the basiliximab group experienced CMV infection, leukopenia, and thrombocytopenia, and this was without any significant difference in any other key safety parameters (including the incidence of serum sickness, fever, lymphoma, and infections in general). Brennan and colleagues reported an international study comparing a short course of antithymocyte globulin (Thymoglobulin ${ }^{\circledR} 1.5 \mathrm{mg} / \mathrm{kg}$ intraoperatively and four more daily doses, $n=141$ ) and basiliximab (20 $\mathrm{mg}$ on days 0 and $4, \mathrm{n}=137$ ) in patients at high risk for acute rejection or DGF who received a deceased-donor renal transplantation. ${ }^{95,96}$ Both groups received CsA-ME, $\mathrm{MMF}$, and steroids for maintenance immunosuppression. 
The antithymocyte globulin group, as compared with the basiliximab group, had lower incidences of BPAR (16\% vs $26 \%, P=0.02$ at one year) and antibody-treated BPAR $(1.4 \%$ vs $8 \% ; P=0.005$ at one year). The antithymocyte globulin group and basiliximab group had similar incidence of DGF (40\% vs 45\%), graft survival (91\% vs 90\% at one year, $69 \%$ vs $63 \%$ at five years) and patient survival ( $96 \%$ vs $96 \%$ at one year, $76 \%$ vs $80 \%$ at five years). The incidence of all adverse events, serious adverse events, and cancers were also similar between the two groups at one year. The patients receiving basiliximab had a lower incidence of infection ( $86 \%$ vs $75 \%$; $P=0.03$ at one year); contrary to other studies, the incidence of CMV disease was higher in the basiliximab group ( $8 \%$ vs $18 \% ; P=0.02$ at one year). These findings suggest that incidence of acute rejection is comparable with IL-2RA and antithymocyte globulin in kidney transplant recipients at low-immunological- risk, but the risk of rejection may be higher with IL-2RA in patients at high risk.

\section{IL-2RA vs alemtuzumab}

Kaufman and colleagues reported a nonrandomized, retrospective sequential study comparing outcomes in kidney transplant recipients induced with either alemtuzumab $(n=123)$ or basiliximab $(n=155)$ in combination with a steroid-free maintenance protocol using TAC and MMF. ${ }^{97}$ The one-year actual death-censored graft survival rates for recipients who received alemtuzumab and basiliximab were both 99\%; the one-year actual patient survival rates were $97 \%$ vs 99\% (NS). A lower rate of early (<3 months) rejection was observed in the alemtuzumab versus the basiliximab group ( $4 \%$ vs $12 \%$, respectively), but the rates for both groups were equivalent at one year (15\% and 14\%). At one year, serum creatinine concentration was similar $(1.42 \pm 0.59 \mathrm{mg} / \mathrm{ml}$ for the alemtuzumab group and $1.36 \pm 0.48 \mathrm{mg} / \mathrm{ml}$ for the basiliximab group). The incidence and etiology of infectious disease were very similar: CMV infection occurred in $4 \%$ and $5 \%$ of the recipients in the alemtuzumab and basiliximab groups, respectively. The incidence of CMV in CMV-naïve recipients who received CMV-positive donor organ were $21 \%$ and $19 \%$ in the respective two groups. Authors concluded that alemtuzumab induction therapy was similar in efficacy to basiliximab in a steroid-free maintenance immunosuppressive protocol for kidney transplant recipients.

At our institution, Ciancio and colleagues randomized 90 first deceased-donor renal transplant recipients ( $>50 \%$ nonCaucasian) into three different antibody induction agents: group A received rabbit antithymocyte globulin, group B alemtuzumab, and group $\mathrm{C}$ daclizumab. ${ }^{98,99}$ Maintenance immunosuppression included TAC and MMF in all three arms, and corticosteroids in groups $\mathrm{A}$ and $\mathrm{C}$ only. The targeted trough TAC level was $8-10 \mathrm{ng} / \mathrm{ml}$ for groups A and $\mathrm{C}$, with a targeted MMF dose of $1 \mathrm{~g}$ twice daily. In group B, target trough TAC level was 4-7 ng/ml (to reduce long-term nephrotoxicity), with $500 \mathrm{mg}$ twice-daily doses of MMF and without corticosteroid maintenance. In a 15-month median postoperative interval report, there were no notable differences in demographics or patient and graft survival. ${ }^{98}$ However, a following report with a minimum follow-up of 27 months showed significantly poorer death-censored graft survival in group B as compared with group A and C combined $(P=0.01) .{ }^{99}$ BPAR rates at one year were equivalent, ie, 5 of 30 in all three groups (17\%). Longer follow-up again showed equivalent BPAR rate, but higher incidence of chronic allograft nephropathy in group B $(37 \%$, $P=0.008)$ as compared with group A (17\%) and group $\mathrm{C}$ $(10 \%)$. In group $B$, there was slightly lower renal function throughout the observation. There was also significantly more leukopenia, but a greater percentage of $\mathrm{T}$ regulatory cells and number of Fox-P3 mRNA copies in group B. There were no differences in other adverse events. These results indicate that with the alemtuzumab induction, $80 \%$ of patients remain steroid-free two years postoperatively; however, they have higher incidence of immunological graft loss, chronic allograft nephropathy, and poor renal function. IL-2RA induction with conventional maintenance immunosuppression may be superior to alemtuzumab induction with low maintenance in a certain patient population.

\section{Combination of IL-2RA and other antibodies}

Vincenti and colleagues randomized mainly low-risk patients receiving deceased or living donor kidney graft into three immunosuppressive regimens to test the efficacy of belatacept (selective costimulation blocker, binds CD80 and CD86 of antigen-presenting cells) without CNI maintenance. ${ }^{100}$ Patients in the intensive belatacept group received belatacept $10 \mathrm{mg} / \mathrm{kg} \times 11$ doses in the first six months with subsequent $5 \mathrm{mg} / \mathrm{kg}$ doses every 4-8 weeks; patients in the less-intensive belatacept group received belatacept $10 \mathrm{mg} / \mathrm{kg}$ x five doses in the first three months with subsequent $5 \mathrm{mg} / \mathrm{kg}$ doses every 4-8 weeks; and patients in the CsA group received CsA maintenance. All patients received induction therapy with $20 \mathrm{mg}$ of basiliximab on days 0 and 4, $2 \mathrm{~g}$ of MMF daily, and a corticosteroid-tapering regimen to $5 \mathrm{mg}$ per day. At six months, the incidence of BPAR was similar among the groups: $7 \%$ for intensive belatacept, $6 \%$ for less-intensive 
belatacept, and $8 \%$ for CsA. At 12 months, the measured GFR was significantly higher among patients receiving the intensive and less-intensive belatacept regimens than among those receiving $\mathrm{CsA}\left(66,62\right.$, and $54 \mathrm{ml} / \mathrm{min} / 1.73 \mathrm{~m}^{2}$, respectively; $P<0.05)$. Chronic allograft nephropathy was less common with both regimens of belatacept than with CsA (29\%, 20\%, and 44\%, respectively). Overall, adverse event profiles are in favor of both belatacept regimens, suggesting potential long-term benefit of less toxic antibody therapy with IL-2RA and costimulation blockade.

Finally, Ciancio and colleagues combined truncated daclizumab $(1 \mathrm{mg} / \mathrm{kg} \times 2$ doses on days 0 and 14$)$ and shortcourse of rabbit antithymocyte globulin $(1 \mathrm{mg} / \mathrm{kg} \times$ three doses on days 0,3 , and 5) along with reduced-dose TAC, early steroid withdrawal (one week), and either MMF or enteric-coated mycophenolate sodium for 150 first kidney transplant recipients consisting of 36\% Caucasian, 30\% Hispanic, and 29\% black. ${ }^{101}$ At 12 months, overall incidence of BPAR was $6 \%$ and BPAR requiring antibody treatment was 3\%. One-year patient and graft survival was $99 \%$ and $96 \%$, respectively. The percentage and types of infectious complications requiring hospitalization during the first 12 months post-transplant was acceptably low (14\% for all infection, $0.7 \%$ for CMV infection). The incidence of new-onset diabetes mellitus after transplantation was $11 \%$; gastrointestinal side effects were seen in $16 \%$ of the patients without significant difference by maintenance immunosuppressive regimen. This study demonstrates the efficacy and safety of combined induction therapy with IL-2R and lymphocyte-depleting antibody with low-dose CNI and rapid steroids elimination for an ethnically diverse population of renal transplant recipients.

\section{Conclusions}

The use of antibody induction after kidney transplantation has increased from $25 \%$ to $63 \%$ in the past decade and roughly one half of the induction agent used is IL-2RA, ie, basiliximab or daclizumab. ${ }^{102}$

Evidence supports basiliximab and daclizumab, as compared with placebo, equally reduce incidence of acute rejection without significant increase in incidence and severity of adverse events. In many immunosuppressive combinations, efficacy of IL-2RA for low- and standard-immunological-risk patients is similar to that of lymphocyte-depleting antibodies and the safety profile is usually better than other antibody preparations.

Given the high safety and tolerability profile, IL-2RAs have successfully been used with steroid- and CNI-sparing protocols in order to reduce toxicities of immunosuppressive medications. For low-to-standard risk patients, early steroid withdrawal with IL-2RA seems to be feasible with minimal, if at all, increasing risk of rejection when combined with CNI-based immunosuppressive regimens. In contrast, results of CNI-sparing protocols with IL-2RA have been mixed. CNI withdrawal may be associated with improved renal graft function and minority of patients may benefit from this strategy, CNI minimization, however, often increases risk of acute rejection. Further studies are needed to evaluate the overall benefits of these new strategies on the long-term survival of patients and allografts.

\section{Disclosures}

The authors have no conflicts of interest that are directly relevant to the content of this review.

\section{References}

1. Hariharan S, Johnson CP, Bresnahan BA, Taranto SE, McIntosh MJ, Stablein D. Improved graft survival after renal transplantation in the United States, 1988 to 1996. N Engl J Med. 2000;342(9):605-612.

2. Matas AJ, Gillingham KJ, Payne WD, Najarian JS. The impact of an acute rejection episode on long-term renal allograft survival (t1/2). Transplantation. 1994;57(6):857-859.

3. Almond PS, Matas A, Gillingham K, et al. Risk factors for chronic rejection in renal allograft recipients. Transplantation. 1993;55(4):752-756; discussion 756-757.

4. Nankivell BJ, Borrows RJ, Fung CL, O’Connell PJ, Chapman JR, Allen RD. Calcineurin inhibitor nephrotoxicity: longitudinal assessment by protocol histology. Transplantation. 2004;78(4):557-565.

5. Citterio F. Steroid side effects and their impact on transplantation outcome. Transplantation. 2001;72(12 Suppl):S75-S80.

6. Jamil B, Nicholls K, Becker GJ, Walker RG. Impact of acute rejection therapy on infections and malignancies in renal transplant recipients. Transplantation. 1999;68(10):1597-1603.

7. Kirkman RL, Shapiro ME, Carpenter CB, et al. A randomized prospective trial of anti-Tac monoclonal antibody in human renal transplantation. Transplantation. 1991;51(1):107-113.

8. Reed MH, Shapiro ME, Strom TB, et al. Prolongation of primate renal allograft survival by anti-Tac, an anti-human IL-2 receptor monoclonal antibody. Transplantation. 1989;47(1):55-59.

9. Tighe H, Friend PJ, Collier SJ, et al. Delayed allograft rejection in primates treated with anti-IL-2 receptor monoclonal antibody Campath-6. Transplantation. 1988;45(1):226-228.

10. van Gelder T, Zietse R, Mulder AH, et al. A double-blind, placebocontrolled study of monoclonal anti-interleukin-2 receptor antibody (BT563) administration to prevent acute rejection after kidney transplantation. Transplantation. 1995;60(3):248-252.

11. Nashan B, Moore R, Amlot P, Schmidt AG, Abeywickrama K, Soulillou JP. Randomised trial of basiliximab versus placebo for control of acute cellular rejection in renal allograft recipients. CHIB 201 International Study Group. Lancet. 1997;350(9086):1193-1198.

12. Kahan BD, Rajagopalan PR, Hall M. Reduction of the occurrence of acute cellular rejection among renal allograft recipients treated with basiliximab, a chimeric anti-interleukin-2-receptor monoclonal antibody. United States Simulect Renal Study Group. Transplantation. 1999;67(2):276-284.

13. Kovarik J, Wolf P, Cisterne JM, et al. Disposition of basiliximab, an interleukin-2 receptor monoclonal antibody, in recipients of mismatched cadaver renal allografts. Transplantation. 1997;64(12):1701-1705. 
14. Kovarik JM, Kahan BD, Rajagopalan PR, et al. Population pharmacokinetics and exposure-response relationships for basiliximab in kidney transplantation. The US Simulect Renal Transplant Study Group. Transplantation. 1999;68(9):1288-1294.

15. Kovarik JM, Offner G, Broyer M, et al. A rational dosing algorithm for basiliximab (Simulect) in pediatric renal transplantation based on pharmacokinetic-dynamic evaluations. Transplantation. 2002;74(7):966-971.

16. Vincenti F, Kirkman R, Light S, et al. Interleukin-2-receptor blockade with daclizumab to prevent acute rejection in renal transplantation. Daclizumab Triple Therapy Study Group. $N$ Engl J Med. 1998;338(3):161-165.

17. Nashan B, Light S, Hardie IR, Lin A, Johnson JR. Reduction of acute renal allograft rejection by daclizumab. Daclizumab Double Therapy Study Group. Transplantation. 1999;67(1):110-115.

18. Ahsan N, Holman MJ, Jarowenko MV, Razzaque MS, Yang HC. Limited dose monoclonal IL-2R antibody induction protocol after primary kidney transplantation. Am J Transplant. 2002;2(6):568-573.

19. ter Meulen CG, Baan CC, Hene RJ, Hilbrands LB, Hoitsma AJ. Two doses of daclizumab are sufficient for prolonged interleukin-2Ralpha chain blockade. Transplantation. 2001;72(10):1709-1710.

20. Vincenti F, Pace D, Birnbaum J, Lantz M. Pharmacokinetic and pharmacodynamic studies of one or two doses of daclizumab in renal transplantation. Am J Transplant. 2003;3(1):50-52.

21. ter Meulen CG, van Riemsdijk I, Hene RJ, et al. Steroid-withdrawal at 3 days after renal transplantation with anti-IL-2 receptor alpha therapy: a prospective, randomized, multicenter study. Am J Transplant. 2004;4(5):803-810.

22. Vincenti F, Lantz M, Birnbaum J, et al. A phase I trial of humanized anti-interleukin 2 receptor antibody in renal transplantation. Transplantation. 1997;63(1):33-38

23. Summary of product characteristics for Zenapax (dacliximab). 1997: Report no. RO 24-7375.

24. Strehlau J, Pape L, Offner G, Nashan B, Ehrich JH. Interleukin-2 receptor antibody-induced alterations of ciclosporin dose requirements in paediatric transplant recipients. Lancet. 2000;356(9238):1327-1328.

25. Sifontis NM, Benedetti E, Vasquez EM. Clinically significant drug interaction between basiliximab and tacrolimus in renal transplant recipients. Transplant Proc. 2002;34(5):1730-1732.

26. Kovarik JM, Pescovitz MD, Sollinger HW, et al. Differential influence of azathioprine and mycophenolate mofetil on the disposition of basiliximab in renal transplant patients. Clin Transplant. 2001;15(2):123-130.

27. Amlot PL, Rawlings E, Fernando ON, et al. Prolonged action of a chimeric interleukin-2 receptor (CD25) monoclonal antibody used in cadaveric renal transplantation. Transplantation. 1995;60(7): $748-756$.

28. Thistlethwaite JR, Jr., Nashan B, Hall M, Chodoff L, Lin TH. Reduced acute rejection and superior 1-year renal allograft survival with basiliximab in patients with diabetes mellitus. The Global Simulect Study Group. Transplantation. 2000;70(5):784-790.

29. Ponticelli C, Yussim A, Cambi V, et al. A randomized, double-blind trial of basiliximab immunoprophylaxis plus triple therapy in kidney transplant recipients. Transplantation. 2001;72(7):1261-1267.

30. Ekberg H, Backman L, Tufveson G, Tyden G, Nashan B, Vincenti F. Daclizumab prevents acute rejection and improves patient survival post transplantation: 1 year pooled analysis. Transpl Int. 2000;13(2): 151-159.

31. Bumgardner GL, Hardie I, Johnson RW, et al. Results of 3-year phase III clinical trials with daclizumab prophylaxis for prevention of acute rejection after renal transplantation. Transplantation. 2001;72(5):839-845.

32. Adu D, Cockwell P, Ives NJ, Shaw J, Wheatley K. Interleukin-2 receptor monoclonal antibodies in renal transplantation: meta-analysis of randomised trials. BMJ. 2003;326(7393):789.

33. Iverson AJ, Vick SC, Sarnacki CT, Wright FH Jr. Daclizumab in live donor renal transplantation. Transplant Proc. 2000;32(4):790-792.
34. Vincenti F, Monaco A, Grinyo J, et al. Rapid steroid withdrawal versus standard steroid therapy in patients treated with basiliximab, cyclosporine, and mycophenolate mofetil for the prevention of acute rejection in renal transplantation. Transplant Proc. 2001;33(1-2):1011-1012.

35. Ciancio G, Miller A, Burke GW, et al. Daclizumab induction for primary kidney transplant recipients using tacrolimus, mycophenolate mofetil, and steroids as maintenance immunosuppression. Transplant Proc. 2001;33(1-2):1013-1014.

36. Chowdhury S, Kode RK, Ranganna K, et al. Induction strategy using basiliximab combined with mycophenolate MMF and immediate lowdose cyclosporin is steroid sparing and more effective than OKT3. Transplant Proc. 2001;33(1-2):1057-1058.

37. Chang GJ, Mahanty HD, Vincenti F, et al. A calcineurin inhibitorsparing regimen with sirolimus, mycophenolate mofetil, and anti-CD25 $\mathrm{mAb}$ provides effective immunosuppression in kidney transplant recipients with delayed or impaired graft function. Clin Transplant. 2000;14(6):550-554.

38. Pisani F, Buonomonth O, Iaria G, et al. Preliminary results of a prospective randomized study of basiliximab in kidney transplantation. Transplant Proc. 2001;33(1-2):2032-2033.

39. Vincenti F. Daclizumab: novel biologic immunoprophylaxis for prevention of acute rejection in renal transplantation. Transplant Proc. 1999;31(6):2206-2207.

40. Lawen JG, Davies EA, Mourad G, et al. Randomized double-blind study of immunoprophylaxis with basiliximab, a chimeric anti-interleukin-2 receptor monoclonal antibody, in combination with mycophenolate mofetil-containing triple therapy in renal transplantation. Transplantation. 2003;75(1):37-43.

41. Webster AC, Playford EG, Higgins G, Chapman JR, Craig JC. Interleukin 2 receptor antagonists for renal transplant recipients: a meta-analysis of randomized trials. Transplantation. 2004;77(2):166-176.

42. Ciancio G, Burke GW, Suzart K, et al. The use of daclizumab, tacrolimus and mycophenolate mofetil in African-American and Hispanic first renal transplant recipients. Am J Transplant. 2003;3(8): 1010-1016.

43. Ciancio G, Burke GW, Suzart K, et al. Effect of daclizumab, tacrolimus and mycophenolate mofetil in racial minority first renal transplant recipients. Transplant Proc. 2002;34(5):1617-1618.

44. Meier-Kriesche HU, Kaza H, Palekar SS, et al. The effect of daclizumab in a high-risk renal transplant population. Clin Transplant. 2000;14(5):509-513.

45. Meier-Kriesche HU, Palenkar SS, Friedman GS, Mulgaonkar SP, Goldblat MV, Kaplan B. Efficacy of Daclizumab in an AfricanAmerican and Hispanic renal transplant population. Transpl Int. 2000;13(2):142-145.

46. Ciancio G, Mattiazzi A, Roth D, Kupin W, Miller J, Burke GW. The use of daclizumab as induction therapy in combination with tacrolimus and mycophenolate mofetil in recipients with previous transplants. Clin Transplant. 2003;17(5):428-432.

47. Vincenti F, Ramos E, Brattstrom C, et al. Multicenter trial exploring calcineurin inhibitors avoidance in renal transplantation. Transplantation. 2001;71(9):1282-1287.

48. Tran HT, Acharya MK, McKay DB, et al. Avoidance of cyclosporine in renal transplantation: effects of daclizumab, mycophenolate mofetil, and steroids. J Am Soc Nephrol. 2000;11(10):1903-1909.

49. Ekberg H, Grinyo J, Nashan B, et al. Cyclosporine sparing with mycophenolate mofetil, daclizumab and corticosteroids in renal allograft recipients: the CAESAR Study. Am J Transplant. 2007;7(3): 560-570.

50. Flechner SM, Kurian SM, Solez K, et al. De novo kidney transplantation without use of calcineurin inhibitors preserves renal structure and function at two years. Am J Transplant. 2004;4(11):1776-1785.

51. Flechner SM, Goldfarb D, Solez K, et al. Kidney transplantation with sirolimus and mycophenolate mofetil-based immunosuppression: 5 -year results of a randomized prospective trial compared to calcineurin inhibitor drugs. Transplantation. 2007;83(7):883-892. 
52. Martinez-Mier G, Mendez-Lopez MT, Budar-Fernandez LF, et al. Living related kidney transplantation without calcineurin inhibitors: initial experience in a Mexican center. Transplantation. 2006;82(11):1533-1536.

53. Ekberg H, Tedesco-Silva H, Demirbas A, et al. Reduced exposure to calcineurin inhibitors in renal transplantation. $N$ Engl J Med. 2007;357(25):2562-2575.

54. Nashan B, Curtis J, Ponticelli C, Mourad G, Jaffe J, Haas T. Everolimus and reduced-exposure cyclosporine in de novo renal-transplant recipients: a three-year phase II, randomized, multicenter, open-label study. Transplantation. 2004;78(9):1332-1340.

55. Vitko S, Tedesco H, Eris J, et al. Everolimus with optimized cyclosporine dosing in renal transplant recipients: 6-month safety and efficacy results of two randomized studies. Am J Transplant. 2004;4(4): 626-635

56. Tedesco-Silva H Jr, Vitko S, Pascual J, et al. 12-month safety and efficacy of everolimus with reduced exposure cyclosporine in de novo renal transplant recipients. Transpl Int. 2007;20(1):27-36.

57. Hong JC, Kahan BD. A calcineurin antagonist-free induction strategy for immunosuppression in cadaveric kidney transplant recipients at risk for delayed graft function. Transplantation. 2001;71(9):1320-1328.

58. McTaggart RA, Gottlieb D, Brooks J, et al. Sirolimus prolongs recovery from delayed graft function after cadaveric renal transplantation. Am J Transplant. 2003;3(4):416-423.

59. Boletis JN, Theodoropoulou H, Hiras T, et al. Monoclonal antibody basiliximab with low cyclosporine dose as initial immunosuppression. Transplant Proc. 2001;33(7-8):3184-3186.

60. Parrott NR, Hammad AQ, Watson CJ, Lodge JP, Andrews CD. Multicenter, randomized study of the effectiveness of basiliximab in avoiding addition of steroids to cyclosporine a monotherapy in renal transplant recipients. Transplantation. 2005;79(3):344-348.

61. Kamar N, Garrigue V, Karras A, et al. Impact of early or delayed cyclosporine on delayed graft function in renal transplant recipients: a randomized, multicenter study. Am J Transplant. 2006;6(5 Pt 1): 1042-1048.

62. Mourad G, Karras A, Kamar N, et al. Renal function with delayed or immediate cyclosporine microemulsion in combination with enteric-coated mycophenolate sodium and steroids: results of follow up to 30 months post-transplant. Clin Transplant. 2007;21(3): 295-300.

63. Andrés A, Marcén R, Valdés F, et al. NI2A Study Group. A randomized trial of basiliximab with three different patterns of cyclosporin A initiation in renal transplant from expanded criteria donors and at high risk of delayed graft function. Clin Transplant. 2009;23(1):23-32.

64. Sinclair NR. Low-dose steroid therapy in cyclosporine-treated renal transplant recipients with well-functioning grafts. The Canadian Multicentre Transplant Study Group. CMAJ. 1992;147(5):645-657.

65. Ahsan N, Hricik D, Matas A, et al. Prednisone withdrawal in kidney transplant recipients on cyclosporine and mycophenolate mofetil - a prospective randomized study. Steroid Withdrawal Study Group. Transplantation. 1999;68(12):1865-1874.

66. Vanrenterghem Y, Lebranchu Y, Hene R, Oppenheimer F, Ekberg H. Double-blind comparison of two corticosteroid regimens plus mycophenolate mofetil and cyclosporine for prevention of acute renal allograft rejection. Transplantation. 2000;70(9):1352-1359.

67. Pascual J, Quereda C, Zamora J, Hernandez D. Steroid withdrawal in renal transplant patients on triple therapy with a calcineurin inhibitor and mycophenolate mofetil: a meta-analysis of randomized, controlled trials. Transplantation. 2004;78(10):1548-1556.

68. Cole E, Landsberg D, Russell D, et al. A pilot study of steroid-free immunosuppression in the prevention of acute rejection in renal allograft recipients. Transplantation. 2001;72(5):845-850.

69. Vincenti F, Monaco A, Grinyo J, Kinkhabwala M, Roza A. Multicenter randomized prospective trial of steroid withdrawal in renal transplant recipients receiving basiliximab, cyclosporine microemulsion and mycophenolate mofetil. Am J Transplant. 2003;3(3):306-311.
70. Rostaing L, Cantarovich D, Mourad G, et al. Corticosteroid-free immunosuppression with tacrolimus, mycophenolate mofetil, and daclizumab induction in renal transplantation. Transplantation. 2005;79(7):807-814.

71. Vitko S, Klinger M, Salmela K, et al. Two corticosteroid-free regimens-tacrolimus monotherapy after basiliximab administration and tacrolimus/mycophenolate mofetil-in comparison with a standard triple regimen in renal transplantation: results of the Atlas study. Transplantation. 2005;80(12):1734-1741.

72. Woodle ES, First MR, Pirsch J, Shihab F, Gaber AO, Van Veldhuisen P. A prospective, randomized, double-blind, placebo-controlled multicenter trial comparing early (7 day) corticosteroid cessation versus long-term, low-dose corticosteroid therapy. Ann Surg. 2008;248(4):564-577.

73. Vincenti F, Schena FP, Paraskevas S, Hauser IA, Walker RG, Grinyo J. A randomized, multicenter study of steroid avoidance, early steroid withdrawal or standard steroid therapy in kidney transplant recipients. Am J Transplant. 2008;8(2):307-316.

74. Pascual J, Zamora J, Galeano C, Royuela A, Quereda C. Steroid avoidance or withdrawal for kidney transplant recipients. Cochrane Database Syst Rev. 2009(1):CD005632.

75. Woodle ES, Vincenti F, Lorber MI, et al. A multicenter pilot study of early (4-day) steroid cessation in renal transplant recipients under simulect, tacrolimus and sirolimus. Am J transplant. 2005;5(1): $157-166$.

76. Anil Kumar MS, Heifets M, Fyfe B, et al. Comparison of steroid avoidance in tacrolimus/mycophenolate mofetil and tacrolimus/sirolimus combination in kidney transplantation monitored by surveillance biopsy. Transplantation. 2005;80(6):807-814.

77. Kumar MS, Heifets M, Moritz MJ, et al. Safety and efficacy of steroid withdrawal two days after kidney transplantation: analysis of results at three years. Transplantation. 2006;81(6):832-839.

78. Gallon L, Perico N, Dimitrov BD, et al. Long-term renal allograft function on a tacrolimus-based, pred-free maintenance immunosuppression comparing sirolimus vs MMF. Am J Transplant. 2006;6(7):1617-1623.

79. Montagnino G, Sandrini S, Iorio B, et al. A randomized exploratory trial of steroid avoidance in renal transplant patients treated with everolimus and low-dose cyclosporine. Nephrol Dial Transplant. 2008;23(2):707-714.

80. Alloway RR, Hanaway MJ, Trofe J, et al. A prospective, pilot study of early corticosteroid cessation in high-immunologic-risk patients: the Cincinnati experience. Transplant Proc. 2005;37(2): 802-803.

81. Anil Kumar MS, Moritz MJ, Saaed MI, et al. Avoidance of chronic steroid therapy in african american kidney transplant recipients monitored by surveillance biopsy: 1-year results. Am J Transplant. 2005;5(8):1976-1985

82. Anil Kumar MS, Khan S, Ranganna K, Malat G, Sustento-Reodica N, Meyers WC. Long-term outcome of early steroid withdrawal after kidney transplantation in African American recipients monitored by surveillance biopsy. Am J Transplant. 2008;8(3):574-585.

83. Nair MP, Nampoory MR, Johny KV, et al. Induction immunosuppression with interleukin-2 receptor antibodies (basiliximab and daclizumab) in renal transplant recipients. Transplant Proc. 2001;33(5):2767-2769.

84. Lin M, Ming A, Zhao M. Two-dose basiliximab compared with two-dose daclizumab in renal transplantation: a clinical study. Clin Transplant. 2006;20(3):325-329.

85. Soltero L, Carbajal H, Sarkissian N, et al. A truncated-dose regimen of daclizumab for prevention of acute rejection in kidney transplant recipients: a single-center experience. Transplantation. 2004;78(10):1560-1563.

86. Stratta RJ, Alloway RR, Lo A, Hodge EE. One-year outcomes in simultaneous kidney-pancreas transplant recipients receiving an alternative dosing regimen of daclizumab. Transplant Proc. 2004;36(4):1080-1081. 
87. Ciancio G, Burke GW, Suzart K, et al. Daclizumab induction, tacrolimus, mycophenolate mofetil and steroids as an immunosuppression regimen for primary kidney transplant recipients. Transplantation. 2002;73(7):1100-1106.

88. Ciancio G, Burke GW, Suzart K, et al. Efficacy and safety of daclizumab induction for primary kidney transplant recipients in combination with tacrolimus, mycophenolate mofetil, and steroids as maintenance immunosuppression. Transplant Proc. 2003;35(2):873-874.

89. Kode R, Fa K, Chowdhury S, et al. Basiliximab plus low-dose cyclosporin vs OKT3 for induction immunosuppression following renal transplantation. Clin Transplant. 2003;17(4):369-376.

90. Sollinger H, Kaplan B, Pescovitz MD, et al. Basiliximab versus antithymocyte globulin for prevention of acute renal allograft rejection. Transplantation. 2001;72(12):1915-1919.

91. Lebranchu Y, Bridoux F, Buchler M, et al. Immunoprophylaxis with basiliximab compared with antithymocyte globulin in renal transplant patients receiving MMF-containing triple therapy. Am J Transplant. 2002;2(1):48-56.

92. Abou-Jaoude MM, Ghantous I, Almawi WY. Comparison of daclizumab, an interleukin 2 receptor antibody, to anti-thymocyte globulinFresenius induction therapy in kidney transplantation. Mol Immunol. 2003;39(17-18):1083-1088.

93. Kyllonen LE, Eklund BH, Pesonen EJ, Salmela KT. Single bolus antithymocyte globulin versus basiliximab induction in kidney transplantation with cyclosporine triple immunosuppression: efficacy and safety. Transplantation. 2007;84(1):75-82.

94. Mourad G, Rostaing L, Legendre C, Garrigue V, Thervet E, Durand D. Sequential protocols using basiliximab versus antithymocyte globulins in renal-transplant patients receiving mycophenolate mofetil and steroids. Transplantation. 2004;78(4):584-590.
95. Brennan DC, Daller JA, Lake KD, Cibrik D, Del Castillo D. Rabbit antithymocyte globulin versus basiliximab in renal transplantation. N Engl J Med. 2006;355(19):1967-1977.

96. Brennan DC, Schnitzler MA. Long-term results of rabbit antithymocyte globulin and basiliximab induction. $N$ Engl J Med. 2008;359(16):1736-1738.

97. Kaufman DB, Leventhal JR, Axelrod D, Gallon LG, Parker MA, Stuart FP. Alemtuzumab induction and prednisone-free maintenance immunotherapy in kidney transplantation: comparison with basiliximab induction - long-term results. Am J Transplant. 2005;5(10): 2539-2548.

98. Ciancio G, Burke GW, Gaynor JJ, et al. A randomized trial of three renal transplant induction antibodies: early comparison of tacrolimus, mycophenolate mofetil, and steroid dosing, and newer immunemonitoring. Transplantation. 2005;80(4):457-465.

99. Ciancio G, Burke GW, Gaynor JJ, et al. A randomized trial of thymoglobulin vs alemtuzumab (with lower dose maintenance immunosuppression) vs daclizumab in renal transplantation at 24 months of follow-up. Clin Transplant. 2008;22(2):200-210.

100. Vincenti F, Larsen C, Durrbach A, et al. Costimulation blockade with belatacept in renal transplantation. $N$ Engl J Med. 2005;353(8):770-781.

101. Ciancio G, Burke GW, Gaynor JJ, et al. Randomized trial of mycophenolate mofetil versus enteric-coated mycophenolate sodium in primary renal transplant recipients given tacrolimus and daclizumab/ thymoglobulin: one year follow-up. Transplantation. 2008;86(1):67-74.

102. United States Renal Data System 2007 Annual Data Report Transplantation. Am J Kidney Dis. 2008;51(1):S155-S172.
Biologics: Targets \& Therapy

\section{Publish your work in this journal}

Biologics: Targets \& Therapy is an international, peer-reviewed journal focusing on the patho-physiological rationale for and clinical application of Biologic agents in the management of autoimmune diseases, cancers or other pathologies where a molecular target can be identified. This journal is indexed on PubMed Central, CAS,

\section{Dovepress}

EMBase, Scopus and the Elsevier Bibliographic databases. The manuscript management system is completely online and includes a very quick and fair peer-review system, which is all easy to use. Visit http://www.dovepress.com/testimonials.php to read real quotes from published authors. 